\title{
The Study of Large Plastic Deformation and Fracture of Plates by Blast of Explosives in the Tubes
}

\author{
Boris Khristoforov \\ Leninsky street 38/1 Institute of Geosphere Dynamics RAS, 119334 Moscow \\ *Corresponding Author: khrist@idg.chph.ras.ru
}

Copyright (C) 2014 Horizon Research Publishing All rights reserved.

\begin{abstract}
Experimental studies and calculations of large plastic deformations and fracture of the aluminum alloy plates of different thickness by the shock waves of blasts of powerful explosives in tubes of different lengths and diameters were carried out. The deformations the plates were investigated with a single and consistent impact loading by shock waves. Parameters of shock waves and loads on the plates in the tubes were measured and method of their calculation was worked. The empirical dependences of the maximum residual deflections and increment area of the plates depending on the load pulse parameters and the plates were obtained. Dynamic strength of the aluminum alloy was defined.
\end{abstract}

Keywords Plate, Explosive, Blast, Tube, Shock Wave, Test, High-Speed Photo, Calculation, Technical Applications, Plastic Deformations, Fracture

\section{Introduction}

An ability to concentrate and direct the action of the blast shock wave in tubes is used in oil and gas wells, tunneling, in rocket engines, modeling of natural and technological dynamic processes an explosive type, including blasts of fuel in transport tunnels. The blast stamping of plates is used in the engineering works. Due to increased efficiency of operation the blasts in tubes makes it possible to abandon the blast basins and chambers, to simplify the manufacturing.

However, these applications usually used brisance action of contacting blasts [1, 2]. An approximate theory of explosives blast in tubes with gas when the gas mass was smaller than the mass of explosion products $m$ the results of measurements of shock waves parameters inside tubes with air at the blasts of powerful explosives at their open end are given in $[3,4]$. The discrepancy between the calculated and measured parameters of explosion shock wave was less than $10 \%$, when the gas mass was smaller than the mass of explosion products. The study of the dynamic behavior of materials was carried in [5].

Below are given results of measurements and calculations of large plastic deformations and fracture of the aluminum alloy plates of different thickness by the shock waves of blasts of powerful explosives in tubes of different lengths and diameters. The deformations the plates were investigated with a single and consistent impact loading. Parameters of shock waves and loads on the plates in the tubes were measured and method of their calculation was worked. The empirical dependences of the maximum residual deflections and increment area of the plates depending on the load pulse parameters and the plates were obtained. Dynamic strength of the aluminum alloy was defined. Blasts of explosives in the tubes were made for improved the methods blast stamping, determining the dynamic strength of metals and alloys, development of methods for simulating the dynamic processes of explosive type in science and technology.

\section{Statement of the Tests}

Under the study of large plastic deformation and fracture of plates the blasts took place in the center of the inlet section of steel tubes of length $\mathrm{L}=1,0$ and $0,5 \mathrm{~m}$, radius $\mathrm{r}=0,075$ and $0.046 \mathrm{~m}$, area of the cross section tubes $\mathrm{S}_{\mathrm{t}}=0,0177$ and $0,00664 \mathrm{~m}^{2}$. Plastic explosive charges had a heat of blast $\mathrm{Q}=$ $4,8 \mathrm{MJ} / \mathrm{kg}$, a density of about $1600 \mathrm{~kg} / \mathrm{m}^{3}$, mass $\mathrm{m}=(1-16)$ $10^{-3} \mathrm{~kg}$. Plates of duralumin D16 with yield point $\sigma_{0}=380$ $\mathrm{MPa}$, thickness $\Delta$ near $0,60,0,91$ and $1,87 \mathrm{~mm}$ clamped in a holder with an inner diameter of $200 \mathrm{~mm}$, ensuring against the drawing. The entire assembly with a plate was suspended on a pendulum at end of the tube opposite blast. Ratio of the area $\mathrm{S}_{\mathrm{t}}$ of the blast action in the tubes to the area $\mathrm{S}$ of the plates was $S_{t} / S=0,56$ and 0,21 . The impulse of load I range up to $40 \mathrm{Ns}$ determined by the deviation of the pendulum. After the blasts the maximum residual deflection $\delta$ at the center of the plates, their profile and increase in the area $\Delta \mathrm{S}$ were measured. Additionally the increment of the maximum pressure $\Delta \mathrm{P}_{\mathrm{m}}$ reflected shock wave was measured, as shown in figure $1 \mathrm{a}$, by face piezoelectric sensor in the center of the plates thickness of 3,74 $\mathrm{mm}$ on the pendulum. Pressure-time in the reflected shock wave in the tube was nearly exponential. Sensitive elements sensors were from quartz or 
various piezoelectrics. Calibration of the sensors carried out on the press or blast in the blast chamber. Different recording equipment with a frequency band up to $10 \mathrm{MHz}$ was applied.

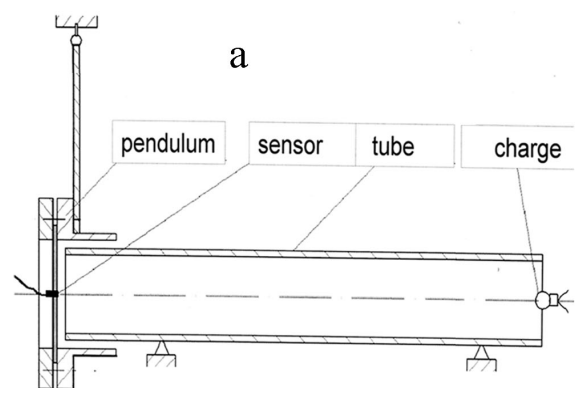

b

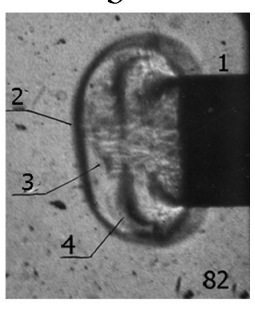

Figure 1. a, b. a - the experimental setup. b - photo a shock wave flowing out from the tube. 1 - tube, 2 - front of shock wave, 3 - contact boundary between the air in shock wave and explosion products, 4 - area of mixed products and hot air behind shock wave.

In some experiments deflection at the center of the plates were measured by electro - contact method and according to the data of high-speed photography. Was used industrial camera SFR-2M with frequency of shooting up to $2.510^{6}$ frames/s or in the version streak camera with resolution up to $210^{-8} \mathrm{~s}$. A typical picture of the strong shock wave flowing from a tube is shown on figure $1 \mathrm{~b}$. Equipment complex applied to measure the actions of blasts in different environments is outlined in $[2,4,6]$. Error of a single measurement by different methods did not exceed $10 \%$.

\section{Results of Tests}

The results of experiments with a single loading by shock waves in tubes are given in tables 1, 2 and figures 2,3 , where introduced the following notation for parameters of loads and plates: I - impulse of reflected shock waves in tubes determined from the pendulum deviation in $\mathrm{Ns}, \mathrm{I} / \mathrm{m}$ - relative impulse, ( $\mathrm{m}$ - mass of explosive charge, ) in $\mathrm{m} / \mathrm{s}, \mathrm{J}=\mathrm{I} / \mathrm{S}_{\mathrm{t}}$ specific impulse in Pas, $\Delta \mathrm{P}_{\mathrm{m}}$ - overpressure of reflected shock wave measured on pendulum by piezoelectric sensor in tubes, $\mathrm{mQ}$ - explosive energy in $\mathrm{kJ}$. Parameters plates have notations: $\mathrm{E}-$ Young's modulus in $\mathrm{MPa}, \delta$ and $\Delta$ deflection and thickness of plates in mm, $v$ - Poisson coefficient, $\sigma_{0}$ - yield point in MPa.

Table 1. The results measuring of the parameters shock waves and the deformation of plates in the single blasts in the tube $1 \mathrm{~m}$ of long.

\begin{tabular}{|c|c|c|c|c|c|c|c|c|}
\hline $\begin{array}{c}\mathrm{m} \mathrm{103} \\
\mathrm{kg}\end{array}$ & $\begin{array}{c}\mathrm{mQ}, \\
\mathrm{kJ}\end{array}$ & $\begin{array}{c}\mathrm{I}, \\
\mathrm{Ns}\end{array}$ & $\begin{array}{c}\mathrm{I}, \\
\mathrm{m} / \mathrm{s}\end{array}$ & $\begin{array}{c}\mathrm{J}, \\
\text { Pas }\end{array}$ & $\begin{array}{l}\Delta \mathrm{Pm}, \\
\mathrm{MPa}\end{array}$ & $\begin{array}{c}\Delta, \\
\mathrm{mm}\end{array}$ & $\begin{array}{c}\delta, \\
\mathrm{mm}\end{array}$ & $\begin{array}{c}\Delta \mathrm{S} / \mathrm{S}, \\
\%\end{array}$ \\
\hline \multicolumn{9}{|c|}{$\mathrm{L}=1 \mathrm{~m}, \mathrm{r}=0,075 \mathrm{~m}, \mathrm{~S}_{\mathrm{t}}=0,0177 \mathrm{~m}^{2}$} \\
\hline 5,0 & 24,0 & 11,3 & 2260 & 640 & 4,8 & 0,91 & 15 & 2,25 \\
\hline 5,5 & 26,4 & 14,4 & 2606 & 810 & 5,2 & 0,9 & 23,2 & 5,04 \\
\hline 7,0 & 33,6 & 14,9 & 2123 & 840 & 5,9 & 0,91 & 25 & 5,93 \\
\hline 8,5 & 40,8 & 21,2 & 2492 & 1200 & 7,8 & 0,91 & 33,3 & 9,57 \\
\hline 9,9 & 47,5 & 23 & 2320 & 1300 & 8,8 & 0,91 & 34,3 & 9,82 \\
\hline 11,0 & 52,8 & 24,8 & 2262 & 1400 & 10 & 0,91 & 37 & 12 \\
\hline 11,0 & 52,8 & 23,8 & 2171 & 1400 & 10 & 0,91 & 37 & 12 \\
\hline 11,1 & 53,3 & 25,6 & 2316 & 1500 & 10 & 0,91 & 36,7 & 11,7 \\
\hline 13,5 & 64,8 & 29 & 2147 & 1600 & 4,8 & 0,91 & 41 & 15,3 \\
\hline 15,8 & 75,8 & 33 & 2090 & 1900 & 12 & 0,92 & 45,3 & 19 \\
\hline 15,6 & 74,9 & 32,8 & 2101 & 1900 & 14,5 & 0,92 & 45 & 18,3 \\
\hline 6,0 & 28,8 & 17,6 & 2933 & 1000 & 14,2 & 1,87 & 12,5 & 1,7 \\
\hline 8,5 & 40,8 & 23,9 & 2809 & 1350 & 5,5 & 1,86 & 15 & 2,23 \\
\hline 11,0 & 52,8 & 29,9 & 2727 & 1680 & 7,7 & 1,86 & 18 & 3,3 \\
\hline 13,5 & 64,8 & 34,2 & 2532 & 1940 & 10 & 1,85 & 23,8 & 4,7 \\
\hline 15,9 & 76,3 & 35 & 2204 & 2000 & 12 & 1,87 & 23,4 & 4,97 \\
\hline 15,9 & 76,3 & 37,8 & 2381 & 2140 & 13,8 & 1,87 & 24,8 & 5,54 \\
\hline
\end{tabular}


Table 2. The results measuring of the parameters shock waves and the deformation of plates at the single blasts in the tubes $0.5 \mathrm{~m}$ of long.

\begin{tabular}{|c|c|c|c|c|c|c|c|c|c|c|}
\hline $\begin{array}{c}\mathrm{m} 10^{3}, \\
\mathrm{~kg}\end{array}$ & $\begin{array}{c}\mathrm{mQ}, \\
\mathrm{kJ}\end{array}$ & $\begin{array}{c}\mathrm{I}, \\
\mathrm{Ns}\end{array}$ & $\begin{array}{c}\mathrm{I}, \\
\mathrm{m} / \mathrm{s}\end{array}$ & $\begin{array}{c}\mathrm{J}, \\
\mathrm{Pas}\end{array}$ & $\begin{array}{c}\Delta \mathrm{P}_{\mathrm{m}}, \\
\mathrm{MPa}\end{array}$ & $\begin{array}{c}\Delta, \\
\mathrm{mm}\end{array}$ & $\begin{array}{c}\delta, \\
\mathrm{mm}\end{array}$ & $\begin{array}{c}\Delta \mathrm{S} / \mathrm{S}, \\
\%\end{array}$ \\
\hline 0,7 & 3,36 & 1,5 & 2138 & 230 & 7,5 & 0,84 & 3,5 & 0,12 \\
\hline 5,5 & 26,4 & 13,7 & 2495 & 2100 & 28,0 & 0,92 & 37,7 & 10,0 \\
\hline 8,1 & 33,6 & 17,7 & 2189 & 2700 & 40,0 & 0,92 & 39,0 & 11,9 \\
\hline 11,0 & 40,8 & 24,5 & 2207 & 3788 & 62,0 & 0,91 & \multicolumn{2}{|c|}{ Plates are damaged on the } \\
edge
\end{tabular}

Table 3 shows the two sets of experiments obtained at multiple sequential loading plates with thickness of $0,6 \mathrm{~mm}$, and their comparison with the data for a single loading plate's momentum equal to the sum of successive pulses. The measured time dependences of the pressures reflected from plates of shock waves is close to the exponential. The deflection and increment area of plates increased with decreasing tube diameter and thickness of plates for a given momentum in tests. Destruction of $0,91 \mathrm{~mm}$ thick plates was obtained at the blasts in a tube radius of $0,046 \mathrm{~m}$ at $\mathrm{I}=18 \mathrm{Hs}$, $\delta>40 \mathrm{~mm}, \Delta \mathrm{S} / \mathrm{S}>12 \%$. The destruction of the plates were occurred at the place entrapment plate by holder. The typical value of the measured maximal and residual deflections plates in one of the experiments were 48 and $46 \mathrm{~mm}$.

Table 3. The comparison of deflection the plates by single the blasts to deflection plates in series from 3 and 2 the successive blasts about the total mass.

\begin{tabular}{|c|c|c|c|c|}
\hline $\begin{array}{c}\mathrm{m} 10^{3}, \\
\mathrm{~kg}\end{array}$ & $\begin{array}{c}\mathrm{mQ}, \\
\mathrm{kJ}\end{array}$ & $\begin{array}{c}\mathrm{I}, \\
\mathrm{Ns}\end{array}$ & $\begin{array}{c}\delta, \\
\mathrm{mm}\end{array}$ & Notes \\
\hline \multicolumn{5}{|c|}{$\mathrm{L}=0,5 \mathrm{~m}, \mathrm{r}=0,046 \mathrm{~m}, \mathrm{~S}_{\mathrm{t}}=0,00664 \mathrm{~m}^{2}, \Delta=0,6 \mathrm{~mm}$} \\
\hline 8,737 & 41,9 & 1,62 & 47,4 & $\begin{array}{c}\text { The action of the total } \\
\text { momentum }\end{array}$ \\
\hline 3,1 & 14,7 & 0,56 & 20,4 & 1 loading \\
\hline 3,1 & 14,7 & 0,56 & 2,4 & 2 loading \\
\hline 2,88 & 13,8 & 0,51 & 0,8 & 3 loading \\
\hline & & & & \\
\hline 9,35 & 44,0 & 1,74 & 46,5 & $\begin{array}{c}\text { The action of the total } \\
\text { momentum }\end{array}$ \\
\hline 3,06 & 14,7 & 0,52 & 20,3 & 1 loading \\
\hline 6,73 & 32,3 & 1,3 & 11, & 2 loading \\
\hline
\end{tabular}

\section{Discussion}

Experiments of tables 1 and 2 had shown that at single loading the maximum residual deflection $\delta$ and the increase in the area of plate $\Delta \mathrm{S}$ for a given impulse I of shock wave in tube were increased with decreasing radius tubes $\mathrm{r}$ and thickness plates $\Delta$. With tube radius $r=46 \mathrm{~mm}$ the plates of thickness $\Delta=0,91 \mathrm{~mm}$ were destroyed on clamped edge at $\delta>$ $40 \mathrm{~mm}, \Delta \mathrm{S} / \mathrm{S}=12 \%, \mathrm{I}=18 \mathrm{Ns}$. At $\mathrm{r}=75 \mathrm{~mm}$ destruction of plates did not happen even at maximum load and strain parameters $\mathrm{I}=33 \mathrm{Ns}, \mathrm{J}=1900 \mathrm{Pas}, \delta=45 \mathrm{~mm}, \Delta \mathrm{S} / \mathrm{S}=12 \%$. At given $\mathrm{r}$ and $\Delta$ deflection $\delta$ was proportional to the total impulse of the applied load.

We neglected the contribution of the elastic strain in compiling calculation models. The typical values of the maximum $\delta_{\mathrm{m}}$ and residual $\delta$ deflections were close. At the blast of the charge weight $0,015 \mathrm{~kg}$ at the entrance to tube length $\mathrm{L}=1 \mathrm{~m}$ these values were the following: $\delta_{\mathrm{m}}=48$ and $\delta$ $=46 \mathrm{~mm}$. Relationship between the maximum stress $\sigma_{\mathrm{m}}$ and deflection $\delta_{\mathrm{m}}$ in the center of the stretched elastic circular plate is determined by the expression [5].

$$
\left(\delta_{\mathrm{m}} / \Delta\right)\left(1+0,49\left(\delta_{\mathrm{m}} / \Delta\right)^{2}\right)=\sigma_{\mathrm{m}} \mathrm{r}^{2} \Delta / 48 \mathrm{D}
$$

Where $\sigma_{\mathrm{m}}$ - maximum elastic stress, $\mathrm{D}=\mathrm{E} \Delta^{3} / 12\left(1-v^{3}\right), \mathrm{E}$ Young's modulus, $v$ - Poisson coefficient. Assuming $\sigma_{\mathrm{m}}=\sigma_{0}$ of yield strength duralumin, we find that the maximum elastic deflection $\sigma_{\mathrm{m}}$ at $\Delta=0,91$ and $1.87 \mathrm{~mm}$ is close to the plate thickness $\Delta$, and the residual deflection $\delta$ an order of magnitude greater. This good agrees with experimental data.

Effect of concentration of the blast load on the residual deflection was investigated. It was assumed that only a portion of the plate area $\pi r^{2}$ is accelerated, and its kinetic energy is expended on the work of plastic deformation of the entire plate. This is true when the loading time is much shorter than the time bending. Use the equation of motion a plate in the form (2)

$$
d^{2} x / d t^{2}+4 \sigma_{0} x / \rho r^{2}=F(t) / \pi r^{2} \rho \Delta
$$


where $\rho$-density of plate. Designate $\omega^{2}=4 \sigma_{0} / \rho^{2}, \mu=\rho \Delta \pi r^{2}$, $\delta=\mathrm{x}_{\mathrm{m}}$. At $\mathrm{F}=$ const, $\omega \tau<\pi / 2$, we have

$$
\delta=\mathrm{I} / \mu \omega=\mathrm{I} / \pi \mathrm{r} \Delta\left(4 \sigma_{0} \rho\right)^{0,5}
$$

Assuming a spherical shape of the loaded plate and $\delta / R<<$ 1 , to get $\Delta \mathrm{S}=\pi \delta^{2}$. Hence for

$$
\Delta \mathrm{S} / \mathrm{S}=\delta^{2} / \mathrm{R}^{2},(\Delta \mathrm{S} / \mathrm{S}) \Delta^{2} \mathrm{r}^{2}=\mathrm{I}^{2} / 4 \pi^{2} \mathrm{R}^{2} \rho \sigma_{0}
$$

Fig. 2 shows both the dependences $\delta=\mathrm{F}(\mathrm{I} / \mathrm{r} \Delta)$ (3) calculated for different $\sigma_{0}=380$ and $1000 \mathrm{MPa}$ and their comparison with experimental data. The experimental data are lie on linear dependence of $\delta=\mathrm{I} / \mathrm{r} \Delta\left(4 \pi^{2} \rho \sigma_{0}\right)^{1 / 2}$ with a value of $\sigma_{0}=1000 \mathrm{MPa}$ in the limits of experimental error. Therefore $\sigma_{0}=1000 \mathrm{MPa}$ can be interpreted as the dynamic yield stress. The dotted line is calculated with $\sigma_{0}=380 \mathrm{MPa}$ equal to the static yield strength.

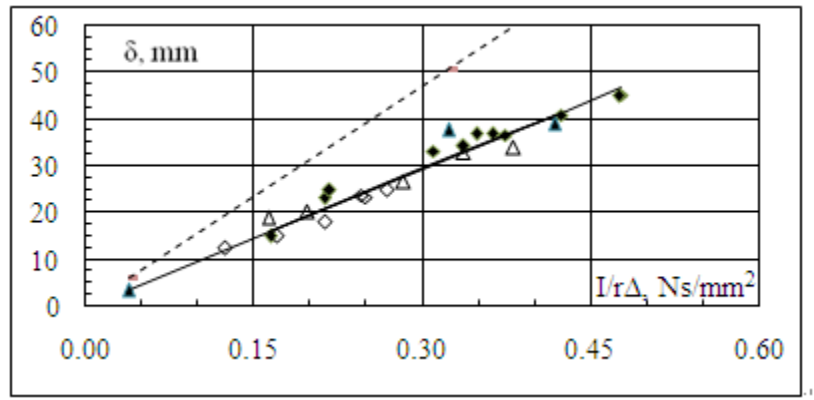

Figure 2. Dependences $\delta=\mathrm{F}(\mathrm{I} / \mathrm{r} \Delta)$. Experimental data: solid markers $\Delta=$ $0,91 \mathrm{~mm}$, transparency markers $\Delta=1,87 \mathrm{~mm}$, rhombs - $\mathrm{L}=1 \mathrm{~m}$, triangles $\mathrm{L}=0,5 \mathrm{~m}$. Calculations: dotted line $-\sigma_{0}=380 \mathrm{MPa}$, solid line $-\sigma_{0}=1000$ $\mathrm{MPa}$.

Fig. 3 shows the dependence $\Delta \mathrm{S} / \mathrm{S}$ as function of $(\mathrm{I} / \mathrm{r} \Delta)^{2}(4)$ calculated by the proposed model with $\sigma_{0}=1000 \mathrm{MPa}$ and its comparison with experimental data. Results of calculations are compared with experimental data for not very large deformations.

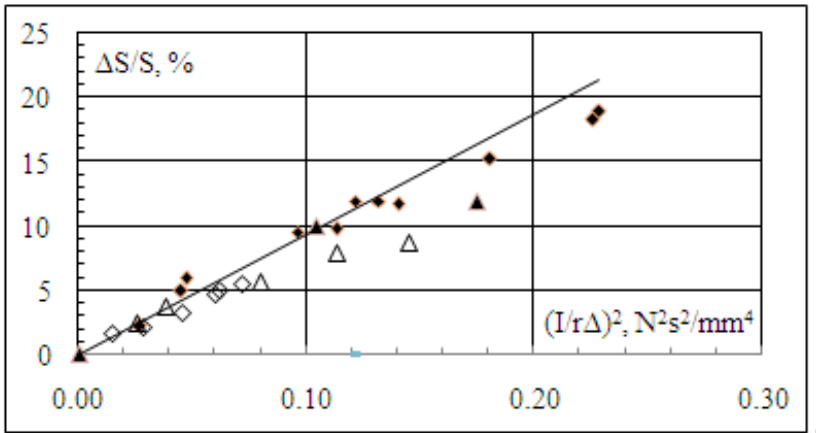

Figure 3. Dependence $\Delta \mathrm{S} / \mathrm{S}=\mathrm{F}(\mathrm{I} / \mathrm{r} \Delta)^{2}$. Experimental data: solid markers $\Delta=0,91 \mathrm{~mm}$, transparency markers $\Delta=1,87 \mathrm{~mm}$, rhombs-

$\mathrm{L}=1 \mathrm{~m}$, triangles $-\mathrm{L}=0,5 \mathrm{~m}$. Solid line - calculation with $\sigma_{0}=1000 \mathrm{MPa}$,

Table 3 shows the experiments obtained at multiple sequential loading plates and their comparison with the data for a single loading plate's momentum equal to the sum of successive pulses. In first series tests the total deflection $\delta_{\mathrm{t}}=$ 23,6 $\mathrm{mm}$ after 3 consecutive loadings total momentum $\mathrm{I}=$
$1,63 \mathrm{Ns}$ is almost half that for a single loading pulse $\mathrm{I}=1,62$ Ns, when deflection $\delta=47,4 \mathrm{~mm}$ on another plate. In second series of experiments on two consecutive loadings with the total momentum $\mathrm{I}=1.82 \mathrm{Ns}$ of deflection $\delta=31.3 \mathrm{~mm}$ was significantly lower than the $\delta_{\mathrm{t}}=46.5 \mathrm{~mm}$ single exposure with momentum $I=1.74$ Ns. This is due to the increase the work of elastic deformation with increasing initial deflection the plates caused by their preceding loading.

\section{Summary}

The results of studies of large plastic deformation and fracture of plates of different thickness of aluminum alloy under loading the shock waves the blasts of powerful explosive charges in tubes of different lengths and diameters are presented. The experiments were performed with a single and consecutive of momentum loading the plates. The parameters of the shock wave and the loads on plates in tubes were measured and methods of their calculation were developed. Based on the proposed models the empirical dependences of the maximum residual deflection and the change of plate area from the impulse of load were derived. Comparison of calculations and experiments was carried out. Dynamic strength of the alloy was defined. It is shown that the successive loads of the plate by series of pulses load are less efficient than a total momentum load.

Blasts of explosives in the tubes were made for improved the methods blast stamping and determining the dynamic strength of metals and alloys. Studies have shown that the blasts in the tubes can improve the technology of blasting to get rid of the expensive equipment and explosive cameras.

\section{Acknowledgements}

I am very grateful to professors G.G. Kocharyn and V.M. Tsvetkov for useful discussion of the directions beneficial use of blasts in tubes in science and technology and constructive suggestions to improve this article. I also thank of Markov V.K and Ignatov A.A for help with the experiments.

\section{Designations}

$\mathrm{L}, \mathrm{r}-$ length and radius of tubes in $\mathrm{m}$.

$\mathrm{S}_{\mathrm{t}}=\pi \mathrm{r}^{2}$ - area of cross section of tube in $\mathrm{m}^{2}$.

$\sigma_{0}=380$ MПа yield point. thickness

$\Delta$ - thickness of plate in $\mathrm{mm}$.

$\rho$ - density in $\mathrm{kg} / \mathrm{m}^{3}$.

$\mathrm{S}_{\mathrm{t}} / \mathrm{S}$ - ratio of the area of the blast action in the tubes to the area of the plates.

$\delta$ - deflection in $\mathrm{mm}$.

$\Delta \mathrm{S}$ - residual increase the area of plates after blast in $\mathrm{m}^{2}$. $\mathrm{Y}$ - Poisson coefficient. 
$\sigma_{\mathrm{m}}$ - maximum elastic stress in MPa.

$\mathrm{E}$ - Young's modulus in $\mathrm{Pa}$,

$\mathrm{Q}$ - heat of blast in $\mathrm{MJ} / \mathrm{kg}$.

$\mathrm{m}-$ explosive mass in $\mathrm{kg}$.

$\mathrm{D}=\mathrm{E} \Delta 3 / 12\left(1-v^{3}\right)$.

$\mathrm{E}$ - Young's modulus in MPa.

I - impulse of load determined by the deviation of the pendulum in Ns.

$\mathrm{J}-\mathrm{I} / \mathrm{S}_{\mathrm{t}}-$ specific impulse in Pas.

$\Delta \mathrm{P}_{\mathrm{m}}$ - maximum pressure (overpressure) of reflected shock wave in MPa.

\section{REFERENCES}

[1] W.E. Baker, P.A. Cox, P.S. Westine, J.J. Kulesz, R.A. Strehlow. Explosion Hazard and Evaluation, Elsevier Scientific Publishing Company, New York, 1983
[2] B.D. Khristoforov. The effect of properties of the source on the action of explosion in air and water, Journal of Combustion, Explosion and Shock Waves, Vol. 40, No.6, 714 $-719,2004$.

[3] B. Khristoforov. Investigation of shock wave parameters at explosives blasts in the tubes with air. Universal Journal of Engineering Science 1(2): 28-33, 2013

[4] E.K. Anderzhanov, B.D. Khristoforov. The study of shock waves in tube at spherical explosion, Journal of Applied Mechanics and Technical Physics, No.5, 25 - 27, 1988.

[5] Meyers M.A. Dynamic behavior of materials. New York: Wiley, 1994. 283 p.'

[6] V.V. Garnov, B.G. Goryunov, N.M. Sitsinskaya. High-speed photographic recording equipment for recording nuclear explosions and other fast processes. Journal of Combustion, Explosion and Shock Waves, Vol. 40. No.6, 729-733, 2004. 